History) preserved and studied the animal material found.

Hitherto, scholars have spoken of Baltic Forest Cultures of Mesolithic age, and have admired the wealth of barbed bone points and flint core-axes and microliths found on Danish Maglemosean sites dated to the Boreal period. The very limited quantity of similar material found in Britain, and the barbed point dredged up from the Dogger Bank, led to the assumption that there had been a diffusion of Baltic influence westward across the former dry bed of the North Sea. In this book Prof. Clark and his colleagues show us the Yorkshire countryside of Late Glacial and early Post Glacial times, and set in this environment we see a small Maglemosean lakeside settlement dated to 7500 B.C., which yielded more than twelve hundred flint implements, almost two hundred barbed points, and many other interesting artefacts. The settlement is clearly earlier than its Danish counterparts and cannot be derived from them.

The most exciting discoveries were the antler head. dresses. Skulls of male red deer, sufficiently mature to carry well-formed antlers, but still young enough not to be burdened by excessive antler weight, were selected. The skull was cut away, leaving the antlers attached to a base-plate which was thinned down and pierced by two holes. The antlers were lightened by thinning and hollowing, but the natural profile was retained. Antlers so elaborately prepared must have been worn as a head-dress, either in hunting or in ceremonial.

Summing up, Prof. Clark skilfully silhouettes the Maglemosean (s.l.) cultures of north-west Europe against the rapidly changing environment of the Late Glacial and early Post Glacial periods. We first see a group of Palæolithic people with Aurignacian and Magdalenian traits who utilized the burin to cut splinters out of antlers; the splinters were worked up into implements. On the Late Glacial parktundras the reindeer was abundant, and the Hamburgian folk utilized reindeer antler only. In the birch woods of the Pre-Boreal period, red deer and elk were common, and at Star Catr the antlers of these animals were the principal raw material, though the bones of the elk and the urus were sparingly used. In the high forest of the Boreal period red deer was still common, and on the Danish sites the bones, rather than the antlers, of this animal were chiefly used.

Such important material demanded adequate publication, and Prof. Clark and the Cambridge University Press have produced a more than adequate book. There is a schedule which describes all the antler points ; twenty-five are illustrated in half-tone, and line-drawings (showing three aspects) are given of one hundred and twenty. The scheduling of the one hundred and four antlers from which splinters had been cut seems scarcely justified. When so much illustration was available, it is to be regretted that the "curious spoon-like object" made from elk antler, which is only poorly shown in a preliminary publica. tion, was not illustrated more clearly. 'The reduction of the illustrations is as consistent as the exigencies of size allowed, and has obviously been carefully thought out. The same cannot be said of the scales of linear measurement used. Inches, fractions of an inch, decimals of an inch, centimetres and millimetres follow one another almost on successive pages. Treatment of percentages is also uneven. When seventeen thousand flints are divided into three groups, the percentage value of the groups can certainly be carried to the first place of decimals; but when thirteen barbed points are similarly divided, little is gained by expressing the relationship of the groups by percentage values. When space has not been at a premium in the main body of the book, it seems ungracious to use a smaller face of type in the short appendix contributed by Mr. Moore. It is unfortunate that the only error also occurs here; Fig. 80 does not correspond with its caption.

The comments of the preceding paragraph do not take away from the high value to be placed on this book, which will for years to come be studied by all interested in the events of the early Post Glacial period in Europe.

G. F. MrTCHeLL

\section{COMMONWEALTH UNIVERSITIES YEARBOOK}

\section{Yearbook of the Universities of the Common- wealth}

Thirty-second issue. Pp. Iviii +2026. (London: Association of Universities of the British Commonwealth, 1955.) $63 s$.

THIS, the thirty-second edition of the "Commonwealth Universities Yearbook", follows very elosely the pattern of that published last year, but there are a number of changes, some of which are the result of recent academic developments. Thus, entries are included for the first time for two new university institutions-University College of Rhodesia and Nyasaland, Salisbury, Southern Rhodesia, and the University of Rajshahi, East Pakistan; and for two Canadian institutions which have recently been admitted to the National Conference of Canadian Universities-St. Mary's University, Halifax, Nova Scotia, and Assumption College, Windsor, Ontario. Also, for the first time, an introduction has been added to the New Zealand section, and this gives a general account of university institutions in that country, written by the Registrar of the University of New Zealand. The first appendix, on qualifications for admission to first-degree courses in universities in the United Kingdom, Canada, Australia and South Africa, has been increased to include details of faculty and dopartmental requirements in United Kingdom universities. The third appendix, on postgraduate awards tenable overseas by United Kingdom graduates, has been rearranged under subject headings for convenience of reference.

These are tho major alterations; but, of course, there are a multitude of small changes throughout the work. Generally, it can be said that these latter are additions, for nearly all the universities of the Commonwealth are expanding, some rapidly, and year by year there is a demand for information on fresh topies. Thus the present edition is about a hundred pages longer than the previous one (an increase of about 5 per cent); but the Association is to be commended for keeping the price the same.

There are 111 university institutions in the British Commonwealth which have been granted degreegiving rights in their respective countries, 22 of which are in the United Kingdom. Together they contribute a very considerable fraction of the world's higher learning, and it is obviously a great convenience to have the principal details about them published in a single reference volume. This work amply fulfils such a need. 